\title{
The contribution agriculture waste reinforcement to the floor topping of renovation building architectures: compressive strength test by trial the percentage of the pseudostem of banana dried powder
}

\author{
Prang Subpa-asa ${ }^{1,{ }^{*}, \text { Komson Maleesee }}{ }^{1}$, Shigeyuki DATE ${ }^{2}$, Tetsurou KASAI ${ }^{2}$, Nutchaphon Phromsuwansiri ${ }^{1}$, and $C h a k o r n$ \\ Duangpan $^{1}$ \\ ${ }^{1}$ Civil Engineering Department, Faculty of Engineering, King Mongkut's Institute of Technology Ladkrabang, Bangkok, Thailand, \\ 10520. \\ ${ }^{2}$ Civil Engineering Department, Faculty of Engineering, Tokai University, Kanagawa-pref., Japan, 259-1292.
}

\begin{abstract}
The growing demand of construction around the world has led to an increased usage of concrete. However, convention concrete making materials are not entirely environmental friendly and this has enthused research on seeking greener alternative for concrete production. Agriculture industries are one of the major industries globally that harvested products such as food and biomass for organism around the world. After harvesting products, there are effluence of agriculture waste as left, straw and pseudostem. This research focusing on mechanical properties as compressive Strength Test of mortar cement adding with the pseudostem of banana dried powder (PBDP) by trial the percentage of PBDP and chemical properties as using scanning electron microscope (SEM). These findings indicate that $10 \%$ of PBDP replacement is the best ratio and element of PBDP which $\mathrm{C}$ was the most element in PBDP as 59.96\% of mass and $71.49 \%$ of atomic.
\end{abstract}

\section{Introduction}

Nowadays, to build new constructions in Thailand, approval drawing is required. There are also rules, standards and restrictions to follow. Meanwhile there are many constructions that have been built for more than 10 years in Thailand. As a result, building renovation is more popular. The renovation more concerns the theory of structure which in Thailand used American concrete institute (ACI) design standard for design the building. Consequently, superimposed dead load (SDL) like decorating, celling and system work be able to significant factor that affect to renovate construction. Thus, the research was focusing on renovate construction affect so the example was floor leveling method by pouring the concrete topping to searching for the materials reinforcement to compressive strength and lighten weight materials.

Agriculture farming is one of the major industries globally as most of the harvested agricultural products are sources of food of people around the world. Countries such as China, India, United States, Brazil and Nigeria are among the world's largest producer of agriculture products, which include cereal, vegetable, and fruits. [1]. However, after harvesting and consumption of the agricultural products, there are abundance of waste materials leftover, such as leaf, straw, stalk and ash. Most of these agriculture wastes are disposed to the surrounding and there is little effort in reusing these materials. In recent times, researchers have begun to utilize these wastes as partial replacement for conventional concrete-making materials and came up with interesting findings. While the use of agriculture wastes in concrete such as those from palm oil, coconut, sugarcane and paddy industry were well documented in the past. [2]

The agriculture in Thailand, among the total area of 520 million square kilometers, more than $65 \%$ is occupied by agriculture related activity. With the everincreasing market demand for agricultural products, most of the agricultural residues often end up in the municipal waste streams and not efficiently. [2] The area for growing the banana is 760.72 square kilometers, the largest area of cultivated banana growing up to 461.72 square kilometers with 773,732 tons per year and increasing 13.4 percent a year. [1]

Banana fiber could play role in emerging bioeconomy. Currently, millions of tons of banana pseudostem are dumped as waste and most of the

* Corresponding author: prangsub@gmail.com 
farmers are facing huge problems in disposing the accumulated banana pseudostem.[3]

Hence, this paper will be researching on the properties of construction materials as cement and aggregate which renewable agriculture waste for sustainable environment friendly.

The banana plant is the largest herbaceous flower plant (2-16m in height), composed of long fibers strongly overlapping forming a pseudostem. Banana trees produce generally 30 large leaves (almost $2 \mathrm{~m}$ long and $30-60 \mathrm{~cm}$ wide). The pseudostem of banana was studied. [4] Banana grows in variety of soil and grows by corm structure. They are tall and fairly study, there are often mistaken for tree but it is actually a "false stem" or "pseudostem". After fruiting, the pseudostem dies, but offshoots will normally have developed from the base, so that the plant as a whole is perennial. As a result, the agriculture industries waste has been affected to environment.

According to [5] the banana leaf ash (BNNLA) consisted mainly of silica, which was about $49 \%$ and the loss on ignition was about $5 \%$. The Blaine's specific surface area and specific gravity of the BNNLA was about $14,000 \mathrm{~cm}^{2} / \mathrm{g}$ and 2.44 , respectively.

Due to the higher fineness of the BNNLA compared to cement, [5] observed that the BNNLA had filler effect which contributed to the lower amount of entrained air in mortar specimens with up to $10 \%$ BNNLA cement replacement level. Similarly, the compressive and tensile strength of concrete specimens containing up to $20 \%$ BNNLA were approximately $12 \%$ and $20 \%$ higher respectively than the corresponding control concrete. In addition, the incorporation of BNNLA reduced the tendency of concrete specimens towards corrosion [5]

\section{Methodology}

\subsection{Materials and Mix propoties}

Banana fiber (Musa sapientum) obtained from the pseudostem of plant by production in Ladkrabang district, a suburb area in Bangkok, Thailand. Banana fiber was expected from the pseudo stem (average diameter of $200 \mathrm{~mm}$ ) of the banana plant. The pseudostem were cut in parts about $5 \mathrm{~mm}$ in length using long knife and then dried in a hot air oven at $60^{\circ} \mathrm{C}$ for 48 hours. [6] They were further cut in a knife mill to get banana powder of sieves NO.30 (600 microns) which show in fig 1 . The material used and its quality was show in table 1 . The pseudostem of banana dried powder used by the percentage of sand replacement that show in table 2
The mortar reference mix proportion were 1:1 (Portland cement type1: Sand pass sieve NO.30) by mass(w/w). PBDP were adding 10\%, 20\%, 30\%, 40\% and $50 \%$ by replacement sand. The compressive strength of the PBDP mortar were determine at age of 7 days using dimensional specimens of $50 \mathrm{~mm}$ x $50 \mathrm{~mm}$ x 50 $\mathrm{mm}$.

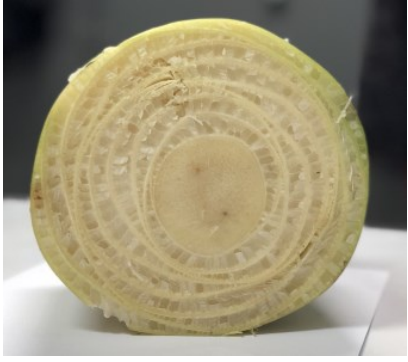

(a)

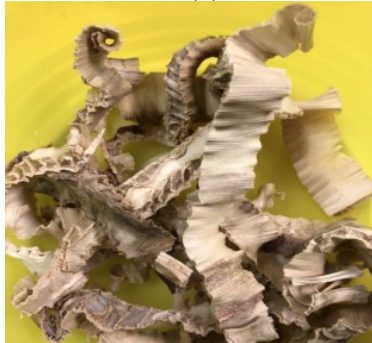

(c)

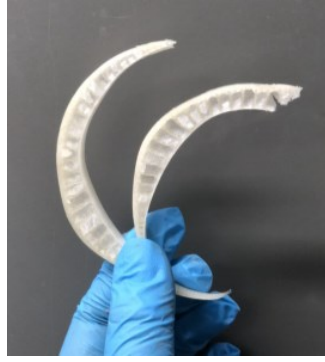

(b)

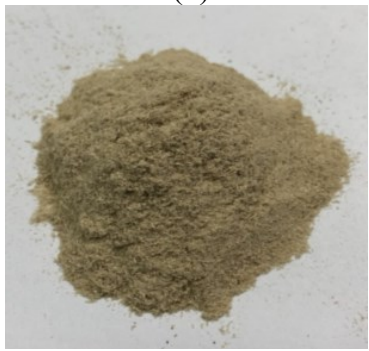

(d)
Fig.1. The pseudostem of banana tree

Fig.1(a) Shows the pseudostem of banana tree used in the present study after cutting for 24 hours.

Fig.1(b) Shows the cutting of the pseudostem about 5 $\mathrm{mm}$ long by removing the cover of pseudostem and cleaning by water (soil)

Fig.1(c) Shows pseudostem that was dried in a hot air oven at $60^{\circ} \mathrm{C}$ for 48 hours.

Fig.1(d) Shows cellulose banana powder, cut in knife mill as 600 microns.

Table 2. Mix proportions

\begin{tabular}{|c|c|c|c|c|c|c|}
\hline$\frac{0}{\bar{E}}$ & $\%$ of PB & C (g.) & PB (g.) & S (g.) & W/C & FF \\
\hline A & 0 & \multirow{5}{*}{1100} & 0 & 1100 & \multirow{5}{*}{0.5} & \multirow{5}{*}{ 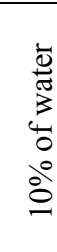 } \\
\hline B & 2.5 & & 27.5 & 1072.5 & & \\
\hline $\mathrm{C}$ & 5 & & 55 & 1045 & & \\
\hline $\mathrm{D}$ & 7.5 & & 82.5 & 1017.5 & & \\
\hline $\mathrm{E}$ & 10 & & 110 & 990 & & \\
\hline
\end{tabular}

Table 1. Materials and properties

\begin{tabular}{|c|c|c|c|}
\hline Materials & Symbol & Properties & ratio \\
\hline Cement & $\mathrm{C}$ & Ordinary Portland cement & 1 \\
\hline Fine aggregate & $\mathrm{S}$ & River sand & 1 \\
\hline Pseudostem of banana & PBDP & Pseudostem of banana dried powder of sieves NO.30 & sand replacement \\
\hline Sikament FF & FF & $\begin{array}{c}\text { A super plasticizing concrete admixture based on Melamine- } \\
\text { Formaldehyde. }\end{array}$ & $10 \%$ of water \\
\hline Water & W & - & 0.5 \\
\hline
\end{tabular}




\subsection{Testing}

The chemical phases of PBDP were obtained from scanning electron microscope (SEM)

A scanning electron microscope (SEM) is a type of electron microscope that produces images of a sample by scanning the surface with a focused beam of electrons. The electrons interact with atoms in the sample, producing various signal that contain information about the sample's surface topography and composition. The electron beam is scanned in a raster scan pattern, and the beam's position is combined with the detected signal to produce an image. SEM can achieve resolution better than 1 nanometer. Specimens can be observed in high vacuum in conventional SEM, or in low vacuum or wet conditions in variable pressure or environmental SEM, and at a wide range of cryogenic or elevated temperatures with specialized instruments [7]

The mechanical phases of PBDP were obtained from triaxle tester.

Compressive strength or compression strength is the capacity of a material or structure to withstand loads tending to reduce size. Measuring the compressive strength of a PBDP mortar cement by using Triaxial tester. Standard triaxial System with analogue measurement is the ideal basic solution for performing standard triaxial tests such as effective and total stress laboratories. Measurements of compressive strength are affected by the specific test method and conditions of measurement.

\section{Result and Discussion}

The micrographs of fibers surfaces by using SEM are presented in Fig 3. The surface of PBDP is relatively hairy. The representative element of PBDP are presented in the Fig 3(b) and Table 3 which $\mathrm{C}, \mathrm{O}, \mathrm{K}, \mathrm{Cl}$ and $\mathrm{Mg}$ are $59.96 \%, 25.87 \%, 11.9 \%, 1.84 \%$ and $0.43 \%$ of mass respectively. The number of atomic of $\mathrm{C}, \mathrm{O}, \mathrm{K}, \mathrm{Cl}$ and $\mathrm{Mg}$ are $71.49 \%, 23.15 \%, 4.36 \%, 0.74 \%$ and $0.25 \%$ respectively. The pozzolanic reactivity increased with mass of $\mathrm{C}$ element and affect to compressive strength load.

Table 3. Result of element of PBDP

\begin{tabular}{|c|c|c|}
\hline Element & \% Mass & \%Atomic \\
\hline $\mathrm{C}$ & 59.96 & 71.49 \\
\hline $\mathrm{O}$ & 25.87 & 23.15 \\
\hline $\mathrm{K}$ & 11.90 & 4.36 \\
\hline $\mathrm{Cl}$ & 1.84 & 0.74 \\
\hline $\mathrm{Mg}$ & 0.43 & 0.25 \\
\hline
\end{tabular}

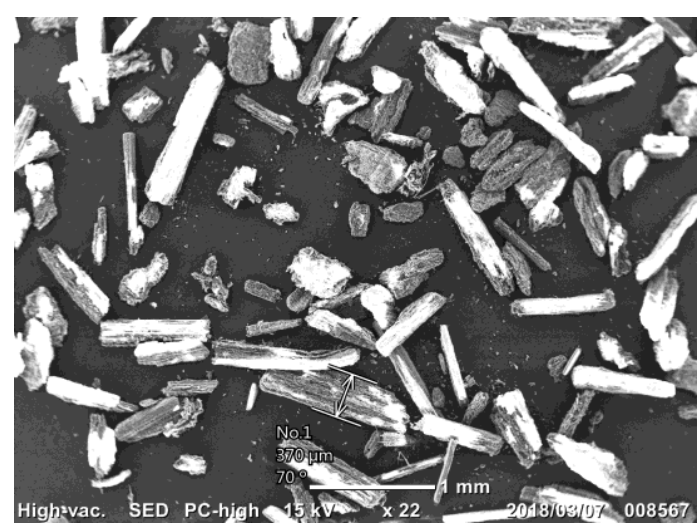

(a)
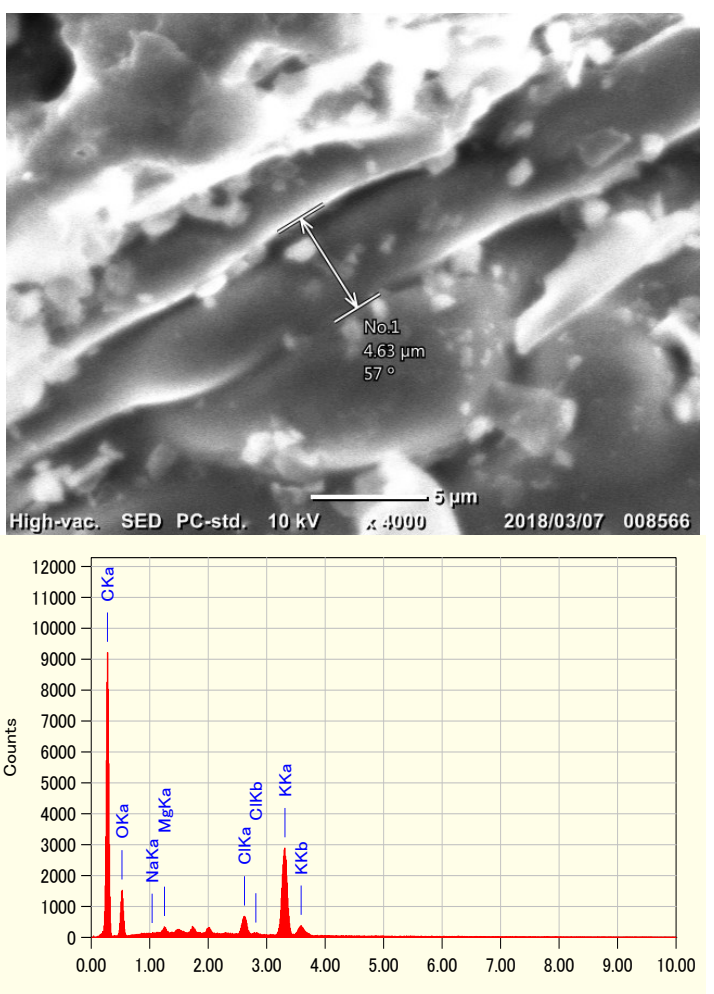

(b)

Fig.3. The result of PBDP by scanning electron microscope (SEM)

The representative of compressive strength of PBDP mortar were measured by triaxial tester in the Table 2 which mass of concrete and water cement ratio controled by mortar cement ratio $1: 1$ (Portland cement type 1 : sand pass sieve NO.30). The general mortar (non-PBDP) on dimensinal specimens of $50 \times 50 \times 50 \mathrm{~mm}^{3}$ were $227.9 \mathrm{ksc}$ of average compressive strength and $1,928 \mathrm{~kg} / \mathrm{m}^{3}$ of cement mortar density. Table 4 was presented result of this study as PBDP sand replacement retio $2.5 \%, 5 \%, 7.5 \%$ and $10 \%$ were $1,788.59 \mathrm{~kg} / \mathrm{m}^{3}$, $1.616 .59 \mathrm{~kg} / \mathrm{m}^{3}, 1,466.26 \mathrm{~kg} / \mathrm{m}^{3}$, and $1,319.27 \mathrm{~kg} / \mathrm{m}^{3}$ of cement mortar density and $4.984 \mathrm{ksc}, 3.205 \mathrm{ksc}, 2.762$ ksc and $3.768 \mathrm{ksc}$ of compressive strength, respectively. Comperision of compressive strength and cement mortar density by ratio were $0.028,0.0020,0.0019$, 0.0029 which are $2 \%, 2.5 \%, 7.5 \%$ and $10 \%$, respectively. 
Table 4. Result of mechanical

\begin{tabular}{|c|c|c|c|c|c|c|c|c|c|c|}
\hline \multirow{2}{*}{$\begin{array}{c}\% \text { of } \\
\text { banana } \\
\text { powder }\end{array}$} & \multirow{2}{*}{$\begin{array}{l}\frac{0}{\tilde{E}} \\
\text { 馬 }\end{array}$} & W & $\mathrm{L}$ & $\mathrm{H}$ & Area & Volumn & Weidge & Density & $\begin{array}{l}\text { Compressiven } \\
\text { strength }\end{array}$ & $\begin{array}{l}\text { Compressive } \\
\text { strength }\end{array}$ \\
\hline & & $\mathrm{cm}$ & $\mathrm{cm}$ & $\mathrm{cm}$ & $\mathrm{cm}^{2}$ & $\mathrm{~cm}^{3}$ & $(\mathrm{Kg})$ & $\left(\mathrm{kg} / \mathrm{m}^{3}\right)$ & $(\mathrm{KN})$ & $(\mathrm{ksc})$ \\
\hline \multirow{3}{*}{$0.0 \%$} & A1 & 4.02 & 5.10 & 5.09 & 20.50 & 104.36 & 0.197 & 1887.784 & 42.250 & 210.069 \\
\hline & $\mathrm{A} 2$ & 3.95 & 5.11 & 5.05 & 20.18 & 101.93 & 0.196 & 1922.856 & 48.900 & 246.957 \\
\hline & A3 & 4.25 & 5.00 & 5.10 & 21.25 & 108.38 & 0.214 & 1974.625 & 47.310 & 226.947 \\
\hline \multirow{3}{*}{$2.5 \%$} & B1 & 4.61 & 5.15 & 5.07 & 23.74 & 120.37 & 0.212 & 1761.245 & 1.562 & 6.707 \\
\hline & B2 & 4.57 & 5.00 & 5.01 & 22.85 & 114.48 & 0.209 & 1825.670 & 1.000 & 4.461 \\
\hline & B3 & 4.35 & 5.01 & 5.03 & 21.79 & 109.62 & 0.195 & 1778.851 & 0.809 & 3.784 \\
\hline \multirow{3}{*}{$5.0 \%$} & $\mathrm{C} 1$ & 4.95 & 5.01 & 5.01 & 24.80 & 124.25 & 0.203 & 1633.862 & 0.911 & 3.745 \\
\hline & $\mathrm{C} 2$ & 4.96 & 5.06 & 5.03 & 25.10 & 126.24 & 0.204 & 1615.958 & 0.656 & 2.664 \\
\hline & $\mathrm{C} 3$ & 5.03 & 5.02 & 5.00 & 25.25 & 126.25 & 0.202 & 1599.962 & 0.794 & 3.205 \\
\hline \multirow{3}{*}{$7.5 \%$} & D1 & 5.07 & 5.03 & 4.99 & 25.50 & 127.26 & 0.184 & 1445.910 & 0.731 & 2.922 \\
\hline & D2 & 5.09 & 4.99 & 5.03 & 25.40 & 127.76 & 0.186 & 1455.884 & 0.550 & 2.207 \\
\hline & D3 & 5.02 & 5.01 & 5.02 & 25.15 & 126.25 & 0.189 & 1496.982 & 0.779 & 3.157 \\
\hline \multirow{3}{*}{$10.0 \%$} & E1 & 5.04 & 5.04 & 4.99 & 25.40 & 126.75 & 0.168 & 1325.402 & 1.085 & 4.354 \\
\hline & E2 & 5.00 & 5.07 & 5.01 & 25.35 & 127.00 & 0.169 & 1330.672 & 0.743 & 2.989 \\
\hline & E3 & 4.99 & 5.04 & 5.04 & 25.15 & 126.75 & 0.165 & 1301.734 & 0.977 & 3.960 \\
\hline
\end{tabular}

\section{Conclusion}

This study investigated the mixing of PBDP sand replacement, compressive strength testing, scanning electron microscope testing were carried out in a ratio can be summarized that the optimal ratio in this study was $10 \%$ sand replacement as $3.768 \mathrm{ksc}$ and $1,319.27$ $\mathrm{kg} / \mathrm{m}^{3}$ of compressive strength and cement mortar density, respectively. As a result, the PBDP mortar cement ratio was $10 \%$ PBDP sand replacement which is the first phase of thesis, The Contribution Agriculture Waste Reinforcement to The Floor Topping of Renovation Building Architectures, that X-ray diffraction, Particle size distribution analyser, curing condition and shrinkage condition are further study.

\section{References}

1. Simpson, S.D., Top Agricultural Producing Countries, (2015) Retrieved from: www.invest opedia.com/financial-edge/0712/top-agriculturalproducing-countries.aspx.

2. C. Visvanathan and C. Chiemchaisri., Management of Agricultural Wastes and Residues in Thailand: Wastes to Energy Approach, International Conference on Agricultural Wastes, Putrajaya, Malaysia, (2006).

3. Mahapatra, D., Mishara, S. and Sutar, N, Banana and its by-product utilization: an overview. Journal Scientific \& Industrial Research, 69: 323329 (2010).
4. Bilba, K., Arsene, Marie-Ange. Ouensanga, A., Study of Banana and Coconut fibers Botanical composition,thermal degradation and textural observations, Bioresource technology, (2015).

5. Kanning, R.C., Portella, K.F., Braganca, M.O.G.P., Bonato, M.M., dos Santos, J.C.M., Banana leaves ashes as pozzolan for concrete and mortar of Portland cement, Construction and Building Material, 54, 460-465 (2014).

6. Ouensanga, A., Variation of fiber composition in sugarcan stalks, Wood and fiber science 21 (2), 105-111 (1989).

7. Stokes, Debbie J., Principles and Practice of Variable Pressure/Environmental Scanning Electron Microscopy (VP-ESEM), Chichester: John Wiley \& Sons. 234 pages (2008). 